\title{
SIMULATION AND EVALUATION OF PRODUCTION FACTORS IN MANUFACTURING OF FIREPLACES
}

\author{
Onofrejova, D. ; Janekova, J. ; Grincova, A. ${ }^{* *} \&$ Soltysova, Z. ${ }^{* * *}$ \\ * Institute of Management, Industrial and Digital Engineering, Faculty of Mechanical Engineering, \\ Technical University of Kosice, Park Komenskeho 9, 04200 Kosice, Slovakia \\ *** Department of Mathematics and Theoretical Informatics, Faculty of Electrical Engineering and \\ Informatics, Technical University of Kosice, Letna 9, 04200 Kosice, Slovakia \\ ${ }^{* * *}$ Department of Industrial Engineering and Informatics, Faculty of Manufacturing Technologies, \\ Technical University of Kosice, Bayerova 1, 08001 Presov, Slovakia \\ E-Mail: daniela.onofrejova@tuke.sk,jaroslava.janekova@tuke.sk, anna.grincova@tuke.sk, \\ zuzana.soltysova@tuke.sk
}

\begin{abstract}
The paper presents quantitative approach for management decisions of the manufacturing system for production of fireplaces, related to evaluation of key parameters - productivity and throughput, which most authors and methodologies consider to be substantial. Methodology was based on creating the simulation model of the fireplace production line in software Witness; optimizing the production capacity by selecting constraints, based on results from simulation model; evaluating the simulation experiments with the goal to increase productivity; setting production to maximize sales profits using Simplex method. Simulation model was built according to a technological process of fireplaces in a semi-automated production. Improvement in a production process within theory of constraints philosophy is complemented by mathematical modelling - Simplex method, that estimate profit maximization in case the company management decides to produce more product variants.

(Received in October 2019, accepted in February 2020. This paper was with the authors 2 months for 1 revision.)

Key Words: Lean Production, Simulation Experiments, Capacity Optimization, Profit Maximization, Simplex Analysis
\end{abstract}

\section{INTRODUCTION}

Generally, factors, such as inputs of goods and services that are inserted into the production process (business) create the final product (output, process value, etc.). According to Samuelson and Nordhaus [1], factors of production can be classified into three categories: land, labour and capital. The production theory describes the production process as a multicriterial and random process. Gutenberg formulates the uncertainty [2] by declaration that there is no direct relationship between input and output at the level of the individual firm. Instead, each firm tries to identify optimal values for several selected controlled parameters, e.g., production speed, operating time, lot sizes, priority numbers, inventory levels, etc., which, in turn, induce the consumption of necessary input factors and the production of a prespecified number of output goods. Different level of management quality in the multi-criterial decision-making process on the shop-floor level results in a kind of waste. Elimination of a waste is a prerequisite in the Lean Production approach, and each waste shall be diminished in all important production factors that influence the entire production system. The concept of the Lean production identifies the following types of a waste: overproduction, overprocessing, inventory, motion, waiting, transport, rework on defects, capabilities of workers (unused). According to [3-5], two basic concepts of Lean thinking exist: eliminating waste and creating a value. Duque and Cadavid [3] present a more detailed framework for Lean production with five basic steps: 1 . Specify Value of the product being chosen by customers; 2. Value Stream Analysis; 3. Continuous Flow; 4. Customer Pull; 5. Continuous Improvement. 
According to the European Commission final report [6], small and medium-sized enterprises (SME) play a decisive role in jobs creation, support of social stability and enhancement of economic drive. However, SMEs face market failures diminishing the conditions in which they operate and compete with other players in areas like finance (especially venture capital), research, innovation and the environment. SMEs fight with difficulties such as the lack of management and technical skills or insufficiencies in labour markets at national level. As SMEs represent $99 \%$ of all businesses in the EU, the most important task for them is to facilitate the development of their economic activities, avoiding the affecting of trading conditions and the common interest [6].

In general, manufacturing process of SME relies on general-purpose machines that are dislocated in several sectors according to the type of technological method used. Usually each product requires a unique technological processing with a sequence of machining. Typical characteristics for such SME job-shop production system are: wide variety of products with low volume, qualified skilled operators able to handle a unique work, large inventory of tools, parts, more detailed planning for technological process sequencing of each product, work centre capacities, and order priorities [7].

Theory of Constraints (TOC) is another widely known management concept $[8,9]$. The study [10] investigates TOC implementation in a medium manufacturing system with products' diversity, where instead of the five-step sequential approach exploiting constraints one after another, the cycles of system productivity target points are proposed. Each improvement cycle simultaneously considers several constraints. Authors stress that the system's constraints should be exploited as a set, and the outcome is a new level of the whole system's productivity. To meet a new level of productivity, it is necessary to improve a variety of means and methods. The studied manufacturing system consumes processes' capacity differently by diverse products. Some irregularities in products and in process utilisation frequently occur in manufacturing systems. In order to determine a bottleneck and to understand the different capacities between processes, the calculation of process engagement is necessary.

The buffer allocation and capacity problem is an important issue in production lines design. New evaluation and optimization methods to allocate buffers in uncertain production lines are presented by [11] and [12]. Markov's process and the aggregation method were used for analysis of different states of the machines and buffers. Zhou et al. [11] evaluates the system availability, not the throughput rate of the line. Production system availability is an important issue, especially when we take into consideration also failure analysis and dependability of the main production system components. To improve system availability is possible also by flexible changing the production configuration, as showed in [13]. Yang et al. apply a genetic algorithm for efficient optimization by changing the production configuration - workers, machines, buffers, and transporters allocations. The Discrete event simulation (DES) modelling method for improving factory logistics processes, using the Plant Simulation software package, was presented in studies [13] and [14]. Aggregate modelling and simulation concepts are presented in [15] and [16].

The comparative analysis of a production system [17] using simulation identified necessary changes in three main components - robots, workers and roller conveyors. Applied changes in the plant layout, group technology, job enlargement and capacity growth increased throughput and average worker utilization in that job shop production system. An insufficient motivation of the workforce may cause a negative impact on the productivity of production lines and business performance. The study [18] examines influence of behavioural and production line factors on subjects working in teams.

Productivity improvement in the large industry is a key prerequisite to attaining competiveness that stimulates the economic growth of a country $[19,20]$. The research study 
investigates with integrated value stream mapping and system simulation methodologies the waste in various processes, bottlenecks that limit the productivity development of a manufacturing environment. The strategic interventions improved stations throughput, and reduced the work-in-progress components created in a system [21-23]. Different methods applied authors in the evaluation of the production processes in mass production presented in [24].

The variety of the presented approaches and our own experience with simulation modelling allow us to summarise the situation as follows. An efficient production with a significant impact on productivity of a manufacturing process may be enabled by retaining a mutual balance between the capacity of the workplace and the load of the workplace in terms of the volume and the timing of production. The restriction requirement of any downtime at work leads to the formation of in-process inventory of semi-finished products. On the contrary, the restriction requirement of in-process inventory for semi-finished products avoiding waiting for further processing between production levels, leads to downtime of machinery and equipment. The complexity of a manufacturing system, multi-criterial and random character of its processes is the main reason for a deep process of analysis and optimization of a production system. Improvement solutions cannot only be focused on a bottleneck; they also require a comprehensive understanding of the production flow through all processes and other potential constraints, considering many criteria, such as the company's business strategy, skills, knowledge assets, financial potential, risks, etc. This is also the main reason why we used in our preliminary case study described further, two different methods to analyse managers' plans for expansion of the products variety.

The aim of this paper is to analyse the capacity requirements, and throughput to achieve the highest productivity in a workplace. First, simulation model was built according to the production process in the workplace. The analysed workplace constitutes a part of the production and performs secondary activity in a medium enterprise. The remaining production area in the company is oriented on different type of engineering production (conveyors), which has a primary position and also impact on the income of the analysed medium enterprise. The concept of producing the fireplaces was a part of an owner's strategy, and the goal is to settle the production and make it efficient and profitable.

\section{MATERIALS AND METHODS}

\subsection{Case study description}

First, the presented case study focuses on the simulation study built in simulation software Witness. Witness is a standard interactive simulation software often used to plan and optimize production, logistics and services. Main applications include: implementation of modern management methods, capacity planning, identification of bottlenecks in production, optimization of production batches, verification of production processes, distribution of production units, reduction of work in progress, quality monitoring, optimization of logistics processes and services, optimization of capital investments.

The presented simulation model describes a technological process of fireplaces in a medium-sized, semi-automated production. The design and a nature of the simulation model was validated referring to analysis of the individual technological operations duration over time, human labour service, while performing quantitative output of finished fireplaces for one shift.

Productivity of a machine, procedure, process, or system over a certain period can be expressed in a figure-of-merit, such as output per hour, cash turnover, a number of shipped orders. The study is based on the interest of the company's owner to produce a new type of products (fireplaces) in the existing plant for the production and renewal of conveyors, also 
because of the unused production area. The production plan includes the production of type A and type B fireplaces (see Table I), which differ in size and price; the manufacturing process is identical. Input parameters are in Table II. The investigation of a company involved collecting data. After analysis of data and creating the model, we consulted and verified the model and its parameters with managers' views, and particular corrections or suggestions.

Table I: Basic input parameters for the products A and B.

\begin{tabular}{|l|c|c|c|}
\hline Input parameters & Unit & Product A & Product B \\
\hline Steel sheet & $\mathrm{mm}$ & 2 & 4 \\
\hline Inter arrival time & $\mathrm{min}$ & 45 & 45 \\
\hline Lot size & $\mathrm{pcs}$ & 17 & 2 \\
\hline Dimensions $(w \times l)$ & $\mathrm{mm}$ & $1250 \times 2500$ & $1250 \times 2500$ \\
\hline Price of steel sheets & $\mathrm{EUR} / \mathrm{pc}$ & 50.78 & 95.13 \\
\hline
\end{tabular}

Table II: Input parameters for the simulation model of the manufacturing process.

\begin{tabular}{|l|c|c|c|c|}
\hline \multicolumn{2}{|c|}{ Input parameters } & Unit & Product A & Product B \\
\hline \multirow{4}{*}{$\begin{array}{c}\text { Machine } \\
\text { cycle time } \\
\left(T_{C}\right)\end{array}$} & Burning & $\mathrm{min} / \mathrm{pc}$ & UNIFORM $(48,52)$ & UNIFORM $(61,69)$ \\
\cline { 2 - 5 } & Bending & $\mathrm{min} / \mathrm{pc}$ & UNIFORM $(53,57)$ & UNIFORM $(68,76)$ \\
\cline { 2 - 5 } & Welding & $\mathrm{min} / \mathrm{pc}$ & UNIFORM $(90,100)$ & UNIFORM $(115,130)$ \\
\cline { 2 - 5 } & Blackening & $\mathrm{min} / \mathrm{pc}$ & 80 & 80 \\
\cline { 2 - 5 } & Assembly & $\mathrm{min} / \mathrm{pc}$ & UNIFORM $(32,38)$ & UNIFORM $(47,53)$ \\
\cline { 2 - 5 } & Packing & $\mathrm{min} / \mathrm{pc}$ & UNIFORM $(8,12)$ & UNIFORM $(12,15)$ \\
\hline Planned total production volume $(Q p)$ & $\mathrm{pcs} / \mathrm{year}$ & 600 & 200 \\
\hline Dimensions $(w \times h \times d)$ & $\mathrm{mm}$ & $423 \times 675 \times 357$ & $592 \times 1,009 \times 442$ \\
\hline Number of shifts & $\mathrm{per} \mathrm{day}$ & 1 & 1 \\
\hline The length of a shift & h/shift & 7.5 & 4 \\
\hline Number of workers & per day & 4 & 2,250 \\
\hline Planned production time & h/year & 2,250 & 3 \\
\hline Planned maintenance & days/year & 3 & 2 \\
\hline Rejects & $\% / Q p$ & 2 & \\
\hline
\end{tabular}

The chronological arrangement of workstations in the experimental model is according to a material flow arrangement in a process of fireplaces manufacturing, and is considering a labour procedure in a production factory. The study also states proposition for optimal number of technological workplaces based on the following measures:

- Waiting time in queues $\left(T_{w}\right)$,

- Average number of elements in buffers $(N)$,

- Maximum efficiency of the total operation and its individual working units $(E)$,

- Increased productivity $(P)$.

The number of operators permits to determine the workshop target cycle time, which in turn allows to establish the parts' plan objective. The requirement is to be able to determine an objective for each configuration anticipated (e.g. 120 parts/hour for four people and 90 parts/hour for three people). It is the most frequent way used for daily tracking of the productivity indicator.

$$
\text { Number of operators }=\frac{\text { Work Load }}{\text { Production Time }}
$$

Work Load (the total amount of work that goes into a part) is the sum of basic tasks performed at each workstation to obtain a complete and good product. It is measured by timing the cycle time of each operator, using the Cycle Time measurement form.

$$
\text { Production time }=\text { Start of the working shift }- \text { Planned stops }
$$


Working shift might run in one, two or three production shifts in an operation performance. Here, start of the working shift is meant as the start of each individual working shift, and planned stops include meetings, preventive maintenance stops, mandatory breaks, stops for tool changeover, etc.

\subsection{Product definition and the manufacturing process}

This preliminary study is focused on the production of the traditional freestanding fireplaces with fireclay padding, as a final product (see Fig. 1). The type of a production is the conventional production. The fireplaces are produced based on the below described manufacturing process and the source material consists of two main parts: $4 \mathrm{~mm}$ and $2 \mathrm{~mm}$ sheets.
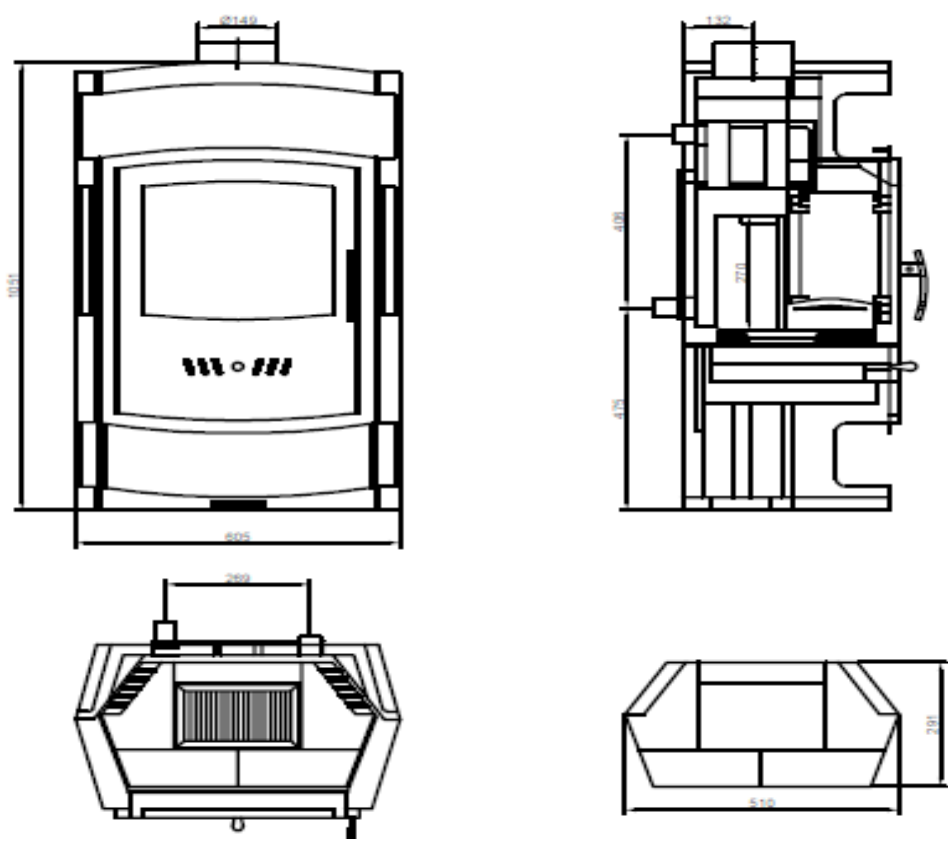

Figure 1: Traditional freestanding fireplace, with fireclay padding.

(Material: cast iron, iron, steel. Wood insert. Dimensions: $605 \mathrm{~mm} \times 1,051 \mathrm{~mm} \times 405 \mathrm{~mm}$ )

For manufacturing, sheets with a thickness of $4 \mathrm{~mm}$ are used: the main combustion chamber $(1 \mathrm{pc})$ and steel grating $(1 \mathrm{pc})$. Next, sheets with a thickness of $2 \mathrm{~mm}$ are used: door $(1 \mathrm{pc})$, the top cover $(1 \mathrm{pc})$, front plate $(1 \mathrm{pc})$, rear plate $(1 \mathrm{pc})$, right and left plate $(1+1 \mathrm{pc})$ bottom sheet $(1 \mathrm{pc})$, sheet metal hinges $(2 \mathrm{pcs})$, the tongue on the handle $(1 \mathrm{pc})$, sheet metal suction opening - regulation (1 pc), box sheet $(1 \mathrm{pc})$, sheet metal - ashtray $(1 \mathrm{pc})$, internal (reinforcing) parts $(4 \mathrm{pcs})$. The production process consists of six technological operations, detailed below (see Fig. 2): Burning (material cutting by laser), Bending, Welding, Blackening, Assembly, Packing. Each operation has specified process time, that includes setup time and process model (see Fig. 2) also describes material flow with specified number of parts created at first process.

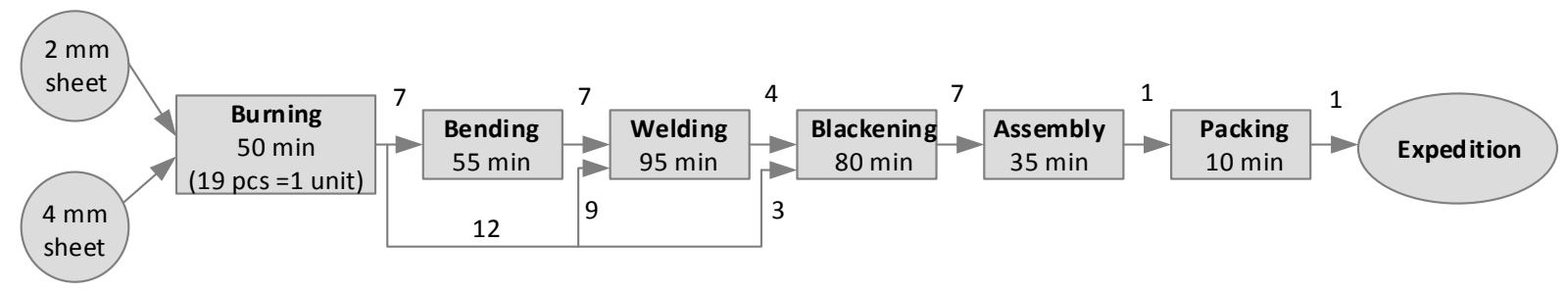

Figure 2: Process model for the production of the freestanding fireplaces. 
At the input process "Burning", there are divided parts from $2 \mathrm{~mm}$ and $4 \mathrm{~mm}$ thick steel sheets. Process "Bending" changes shape of $2 \mathrm{~mm}$ metal sheet parts as: door ( $1 \mathrm{pc})$, the top cover $(1 \mathrm{pc})$, sheet metal - hinges ( $2 \mathrm{pcs})$, box sheet $(1 \mathrm{pc})$, ashtray $(1 \mathrm{pc})$; and $4 \mathrm{~mm}$ sheet follows: the main combustion chamber $(1 \mathrm{pc})$. In the process "Welding", parts exiting the process "Bending" are welded together, with additional 4 units of $2 \mathrm{~mm}$ sheet and 5 units of 2 $\mathrm{mm}$ sheet (side, front, rear, bottom). Process "Blackening" applies blackened finish with longer lasting results for 4 finished welds, and parts: from $2 \mathrm{~mm}$ sheet tab to the regulatory part of the suction opening, and out of $4 \mathrm{~mm}$ sheet a metal grate. Process "Assembly" assemble 7 blackened parts into one unit. At the workplace "Packing", the finished products in quantity of 1 unit are packed for a final expedition [20,21].

\subsection{Simplified mathematical model and optimization by Simplex method}

Simplex algorithm is one of the most often used methods belonging to the Linear programming. Linear programming (LP) is a mathematical method of solving tasks that makes it easier for managers to do optimal decisions when solving tasks from many areas, especially economic ones. In principle, it is necessary to determine the optimal value of a linear function on a set of solutions of a system of linear equations and inequalities. Mathematical modelling is often used to address the problems of optimal use of raw materials, machine time, staff, financial resources and so on. The task of such mathematical modelling is designed to interpret a situation for which the best solution is searched with certain boundary assumptions. The objectives are expressed by means of target function, Eq. (3) and boundary conditions by the system of equations and inequalities, Eqs. (4) and (5). According to the type of target functions and boundary conditions, the model can be linear or non-linear. Let:

$$
\begin{gathered}
z(x)=\sum_{j=1}^{n} c_{j} \cdot x_{j} \\
\sum_{j=1}^{n} a_{i j} \cdot x_{j}\left\{\begin{array}{l}
\leq \\
\geq \\
=
\end{array}\right\} b_{i} \\
x_{j} \geq 0
\end{gathered}
$$

where $c_{j}$ are coefficients of target function, $a_{i j}$ are coefficients of boundary system, $b_{i}$ are coefficients of the right side, $x_{j}$ are decision variables, $i=1,2, \ldots, m$ and $j=1,2, \ldots, n$.

If the target functions and boundary conditions have the form of linear functions occur in the problem of mathematical modelling, the problem of LP can be solved. If there is defined one target function in the LP problem, one-criterion LP problem is being solved.

Simplex method is a universal method for solving linear modelling problems. The simplex method algorithm allows to determine the optimal solution after a final number of steps or to determine that an optimal solution does not exist. Applying this method assumes the problem model in form of Eqs. (3) to (5) redraft in form of Eqs. (6) to (8).

$$
\begin{gathered}
\max (\min ) z(x)=\sum_{j=1}^{n} c_{j} \cdot x_{j} \\
\sum_{j=1}^{n} a_{i j} \cdot x_{j}+s_{i}=b_{i}, \quad b_{i} \geq 0 \\
x_{j}, s_{i} \geq 0
\end{gathered}
$$

where $s_{i}$ are complementary variables, $i=1,2, \ldots, m$. An optimal problem solution is such solution in which a target function acquires its extreme (maximum or minimum). 


\section{RESULTS}

The case study and subsequent analysis of the results were performed for the purpose:

- to create simulation model of the production line for fireplaces,

- based on results from simulation model, to optimize production capacity by selecting constraints,

- to evaluate simulation experiments with the goal to increase productivity,

- to set up production to maximize sales profits.

\subsection{Simulation model}

The simulation model (see Fig. 3) was created and validated for the process of fireplace production in the given workplace. At the first implementation phase the production of two types of fireplaces A and B is considered; fireplace parameters are defined in Table I. Fireplaces differ in size, labour intensity; the technological process of production is equal for both types (see Fig. 2). Simulation modelling examines the throughput of the production system, its bottlenecks to maximize the final output and ensure rationalization of work. The "Base Model" is built and validated according to the technological process illustrated by the process diagram (see Fig. 2) and the estimated production volume (see Table II). In the Base Model, one workstation is considered for each technological operation, the number of operators in the workplace is 4 . The layout of workstations in the production zone is according to the processing sequence of the product, so called product layout. After each finished operation, the semi-finished products are stored in inter-operational buffers (buffer for "CuttedSheets", "BendedParts", etc.), (see Fig. 3). The buffers have a capacity of 20 parts. Production per week in "Base Model" was achieved in quantity of 11 pieces, as is 6 fireplaces type A and 5 fireplaces type B. The statistical outputs of the simulation Base Model are recorded in Fig. 4.

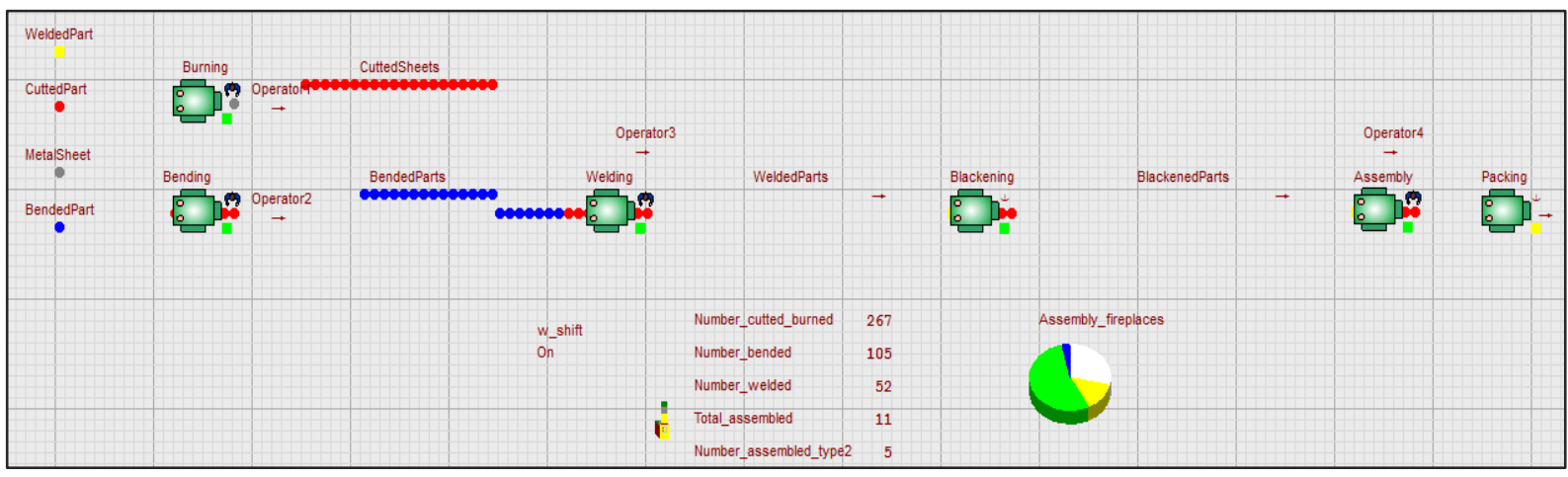

Figure 3: The layout of buffers and workstations in the simulation model as direct deployment in order to achieve one piece flow.

Table III summarizes information for comparing the productivity output, the working capacity of units, the average waiting times of unfinished parts in the individual buffers, average number of entities in buffers.

The monitored parameters of the output statistics resulting from the "Base model", as well as accomplished experiments, that were carried out in order to eliminate the bottlenecks, are specified in Table III and Table IV.

Individual statistics show the workload of workstations and operators. Evaluation refers to bottlenecks in the workstations Welding, Blackening, and from the perspective of the operators in the Welding and Assembly workstations. 

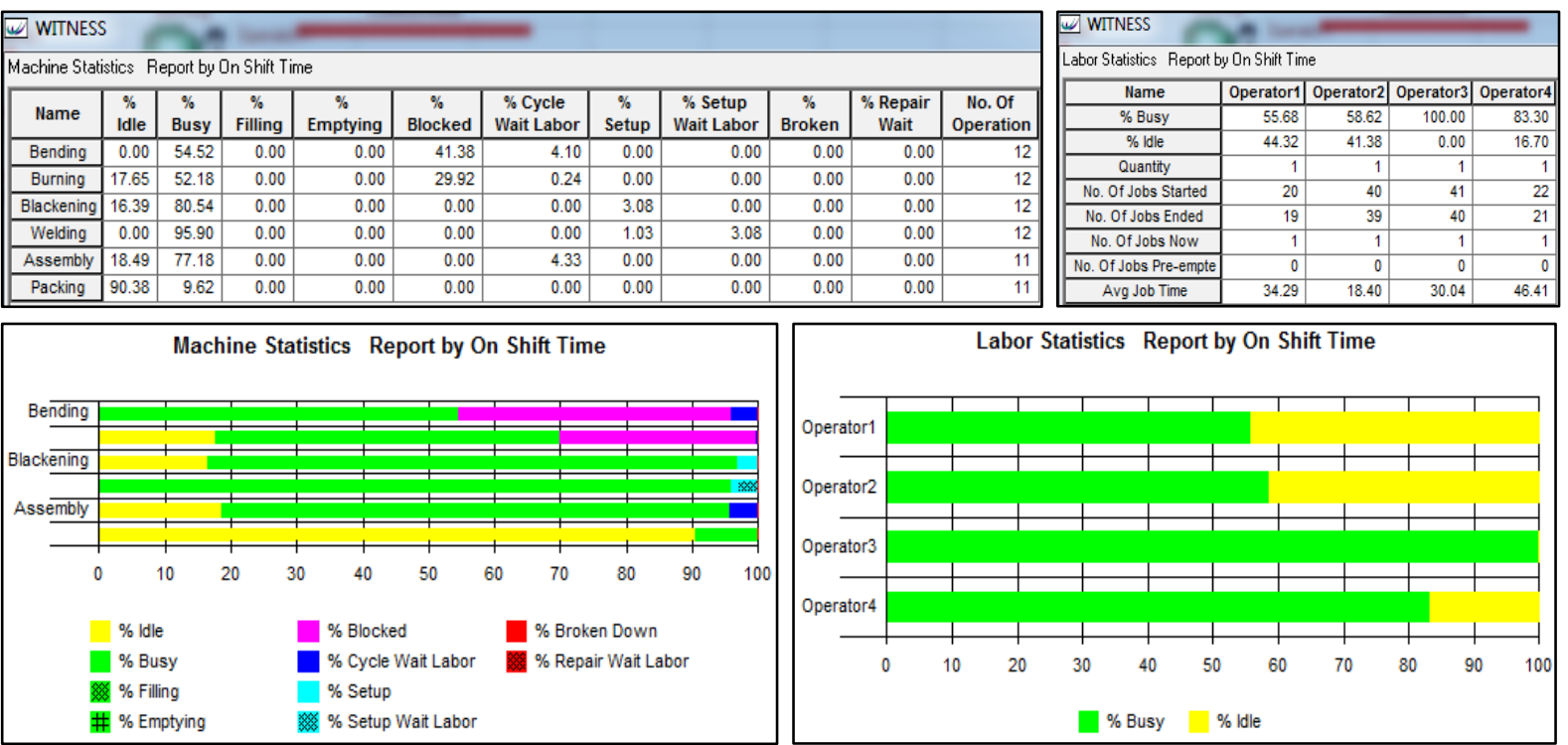

Figure 4: Simulation base model statistics: machine report, labour report.

Table III: Data of interest gathered from the simulation experiments with the model.

\begin{tabular}{|c|c|c|c|c|c|}
\hline Variable & Unit & Operational unit & Base Model & Experiment 1 & Experiment 2 \\
\hline \multirow{2}{*}{$\begin{array}{c}\text { Productivity }(P) \\
(\text { Total / A + B) }\end{array}$} & \multirow{2}{*}{$\begin{array}{l}\mathrm{pcs} / \\
\text { week }\end{array}$} & \multirow[t]{2}{*}{ 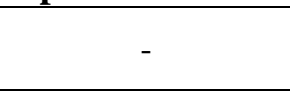 } & 11 & 11 & 15 \\
\hline & & & 6 & 6 & 15 \\
\hline \multirow{8}{*}{$\begin{array}{l}\text { Working capacity of units } \\
\qquad\left(C_{U}\right)\end{array}$} & \multirow{8}{*}{$\%$} & Burning & 52.18 & 73.97 & 63.86 \\
\hline & & Bending & \multirow{2}{*}{$\begin{array}{l}54.52 \\
95.90\end{array}$} & 90.07 & 67.41 \\
\hline & & Welding (1) & & & \multirow{2}{*}{60.50} \\
\hline & & Welding (2) & - & 74.84 & \\
\hline & & Blackening (1) & 80.54 & 44.75 & $\frac{0.08}{47.86}$ \\
\hline & & Blackening (2) & - & 35.01 & 47.58 \\
\hline & & Assembly & \multirow{2}{*}{76.56} & 78.06 & 42.72 \\
\hline & & Packing & & 9.62 & 12.93 \\
\hline \multirow{4}{*}{$\begin{array}{l}\text { Average time of entity } \\
\text { waiting in a buffer } \\
\qquad\left(T_{w}\right)\end{array}$} & \multirow{4}{*}{$\min$} & Cutted Sheets & \multirow{2}{*}{$\begin{array}{l}133.06 \\
272.70\end{array}$} & \multirow{2}{*}{\begin{tabular}{|l|}
63.68 \\
54.54
\end{tabular}} & \multirow{2}{*}{53.13} \\
\hline & & BendedParts & & & \\
\hline & & WeldedParts & 0.00 & 245.82 & 5.54 \\
\hline & & BlackenedParts & 32.55 & 202.51 & 1.26 \\
\hline & & CuttedSheets & 20.00 & 13.78 & 9.66 \\
\hline Average number or & & BendedParts & 16.20 & 4.63 & 0.00 \\
\hline entities in buffers & pcs & WeldedParts & 0.00 & 10.13 & 0.20 \\
\hline & & BlackenedParts & 1.66 & 11.17 & 0.07 \\
\hline
\end{tabular}

Table IV: Data of interest gathered from the simulation experiments with the model - Labour statistics.

\begin{tabular}{|c|c|c|c|c|c|}
\hline Variable & Unit & Operator & Base Model & Experiment 1 & Experiment 2 \\
\hline \multirow{4}{*}{$\begin{array}{l}\text { Labour capacity } \\
\qquad\left(C_{U}\right)\end{array}$} & \multirow{4}{*}{$\%$} & 1 & 61.80 & 78.26 & 65.60 \\
\hline & & 2 & 58.62 & 93.41 & 71.07 \\
\hline & & 3 & 100.00 & 83.78 & 62.77 \\
\hline & & 4 & 86.18 & 67.15 & 53.90 \\
\hline \multirow{4}{*}{$\begin{array}{l}\text { Average job time } \\
\qquad\left(T_{j}\right)\end{array}$} & \multirow{4}{*}{$\min$} & 1 & 27.81 & 35.62 & 38.38 \\
\hline & & 2 & 18.40 & 30.70 & 27.74 \\
\hline & & 3 & 30.04 & 35.76 & 29.82 \\
\hline & & 4 & 40.33 & 47.88 & 23.50 \\
\hline \multirow{4}{*}{$\begin{array}{l}\text { No. of jobs completed } \\
\qquad(N)\end{array}$} & \multirow{4}{*}{ pcs } & 1 & 26 & 27 & 20 \\
\hline & & 2 & 39 & 37 & 31 \\
\hline & & 3 & 40 & 56 & 51 \\
\hline & & 4 & 25 & 18 & 28 \\
\hline
\end{tabular}




\subsection{Optimization of the production capacity by selecting constraints and evaluation of the simulation experiments to increase productivity of the production line}

Based on above mentioned facts, the entire model needs to be optimized to eliminate bottlenecks. The first experiment called „Experiment 1“, is to increase the number of Welding and Blackening workstations. Since Welding requires the presence of an operator and the operator is $100 \%$ busy in this position, an increase in the number of operators for the position as well as the workstation by 1 is necessary. After simulation run in „Experiment 1“, we can assume, that workload at workstations has been reduced and also operators' workload is rather even. When monitoring production, we can assume that it has not increased and remains at total quantity of 11 pieces, as is 6 fireplaces type A and 5 fireplaces type B. The waiting time in buffers "Welded Parts" and "Blackened Parts" has been increased (see Table III), indicating a bottleneck in the Assembly process.

For the next optimization in the experiment called "Experiment 2", we considered the results of the Simplex method, whose findings recommend producing only one type of fireplaces, type $\mathrm{A}$ at an optimum number of 8 pieces per week, ensuring maximum profit from sales (see subchapter 3.3). "Experiment 2" is considering the production of one type of fireplace $\mathrm{A}$, and is based on the settings related to the number of workstations and operators in "Experiment 1". The simulation results in "Experiment 2" point to a final production of 15 A type fireplaces per week. Furthermore, we can also state a more even and lower load on individual production workstations, as well as more balanced performance of operators and their reasonable load with an average value of $63.33 \%$. The waiting time of parts in buffers has also been adjusted, and reduced by $90 \%$.

\subsection{Profit maximization}

Especially in SMEs, with optimized productivity and smoothing of internal processes, a company can handle cost creation, its nature and cost dependence on production volume. Results from simulation study are supplemented by quantitative tool of mathematical modelling, particularly the linear programming approach. The profit maximization criterion is often used for an optimization task. Linear programming method selects the optimal solution according to the specified criteria. The Simplex method is frequently used method of linear programming, which solves the task sequentially. The initial state is refined by successive calculations, merged to other solutions with a more convenient target function until the optimal solution is obtained. Optimizing linear tasks allow to determine the optimal range under given production conditions, raw materials, energy and work resources to minimize costs, minimize waste, maximize profit, and so on.

To solve the problem, a target function $z\left(x_{1}, x_{2}\right)$ with two variables will be used. The aim of the analysis is to find the optimal solution (number of products $x_{1}$ of the A type and number of products $x_{2}$ of the B type of fireplace), in which the function of weekly profit $z\left(x_{1}, x_{2}\right)$ from the sale of produced fireplaces is maximum with predefined boundaries (see Table V).

Table V: Coefficients of target function and boundary conditions.

\begin{tabular}{|l|c|c|c|}
\hline \multicolumn{1}{|c|}{ Index } & Unit & Product A $\left(x_{1}\right)$ & Product B $\left(x_{2}\right)$ \\
\hline Profit from sales $\left(P_{S}\right)$ & $\mathrm{EUR} / \mathrm{pc}$ & 78.4 & 86.7 \\
\hline Base surface $(S)$ & $\mathrm{m}^{2} / \mathrm{pc}$ & 0.15 & 0.26 \\
\hline Cycle time $(C T)$ & $\mathrm{h} / \mathrm{pc}$ & 4.58 & 6.33 \\
\hline
\end{tabular}

Produced fireplaces are stored in a storage space with extent of $38.4 \mathrm{~m}^{2}$. Available working time per week for the production of fireplaces is 37.5 hours during a working shift. With the given conditions, coefficients of the target function and boundary conditions (see Table V), the problem is solved in such a form Eq. (9): 


$$
\begin{gathered}
\max z\left(x_{1}, x_{2}\right)=78.4 \cdot x_{1}+86.7 \cdot x_{2} \\
0.15 \cdot x_{1}+0.26 \cdot x_{2} \leq 38.4 \\
4.58 \cdot x_{1}+6.33 \cdot x_{2} \leq 37.5 \\
x_{1}, x_{2} \geq 0
\end{gathered}
$$

For the purpose of using the Simplex method, the problem formed with equations Eq. (9) needs to be redefined to form Eq. (10):

$$
\begin{gathered}
\max z\left(x_{1}, x_{2}\right)=78.4 \cdot x_{1}+86.7 \cdot x_{2} \\
0.15 \cdot x_{1}+0.26 \cdot x_{2}+s_{1}=38.4 \\
4.58 \cdot x_{1}+6.33 \cdot x_{2}+s_{2}=37.5 \\
x_{1}, x_{2} \geq 0
\end{gathered}
$$

The optimum obtained by solving the problem using the Simplex method is, as follows Eq. (11):

$$
\begin{gathered}
x_{1}=8.19 \\
x_{2}=0 \\
z\left(x_{1}, x_{2}\right)=642.1
\end{gathered}
$$

Based on the result obtained, it can be stated that in the case of profit maximization, it is recommended to produce only the A type of fireplace with assumed weekly profit EUR 642.1.

\section{CONCLUSION}

Manufacturing system is complex, that's why improvement solutions require a comprehensive understanding of the production flow through all processes and other potential constraints. To meet a new level of productivity, the manufacturing system needs to have adopted an improvement solution mix that is composed of a variety of means and methods [10]. Process synchronization and balanced flows are considered as fundamental lean conditions, due to lean production unit. Prerequisites for a balanced flow in a production can be considered the stability in processes from the measure of quality, reliability and time, such as balanced capacities, well operated production environment as logistics, technical preparation for production, administrative, and a production in a small batches. It is obvious, that every system has at least one constraint, which avoids achieving the higher level of performance.

The paper presents quantitative approach for management decisions, related to evaluation of key parameters - productivity, throughput (which most authors / methodologies consider to be substantial) of the manufacturing system for production of fireplaces, and was based on:

- creating the simulation model of the production line for fireplaces in software Witness,

- optimizing the production capacity by selecting constraints; based on results from simulation model,

- evaluating the simulation experiments with the goal to increase productivity,

- setting production to maximize sales profits using Simplex method.

Based on the Theory of Constraints, the aim of this simulation study and the applied whatif analysis was to identify bottlenecks; remove losses in this point by new investment or modification of a system and verifying whether the modification could bring improvements for the entire production system. The target for the medium production company, for which this study was performed, is settling the production with the goal to achieve increase in productivity, efficient production time, optimal number of operators, and high capacity utilization of machines and equipment in a process. 
Base simulation model established production output in a total quantity of 11 fireplaces of both types A and B. Such production system identified bottleneck at the workstations "Welding" and "Blackening", and lead to decision of increasing number of those workstations for 2. Moreover, new bottleneck in operator's position at "Assembly" was found, what lead us to decision increase number of operators at the workstation "Welding" for 2. Production output by such improvements in "Experiment 1" adjustment was not achieved, although improvements in lower workload of workstations were identified.

For the next optimization in the experiment called "Experiment 2", we considered the results of the Simplex method. Profit maximization was analysed by mathematical programming method - Simplex method, estimating the possible implementation of two products (fireplaces A and B) into production process. Results accomplished by calculation claims that implementing also type of fireplace B would be counterproductive in this stage of a production; and in the case of profit maximization, it is recommended to produce only the A type of fireplace with assumed weekly profit rate EUR 642.1. The achieved results in "Experiment 2" show improvements in growth of labour productivity due to the proposed measures compared to the current situation about $36 \%$. Furthermore, we can also state a more even and lower load on individual production workstations, as well as more balanced performance of operators and their reasonable load with an average value of $63.33 \%$. The waiting time of parts in buffers has also been adjusted, and reduced by $90 \%$.

Simulation studies and Simplex method supported the process of management decisionmaking for the fireplace production; we relied on the key parameters of optimization of production processes.

\section{ACKNOWLEDGEMENT}

This work has been supported by grant project KEGA 009TUKE-4/2020.

\section{REFERENCES}

[1] Samuelson, P. A.; Nordhaus, W. D. (2001). Economics, $17^{\text {th }}$ edition, McGraw-Hill Inc., New York

[2] Jahnke, H. (2000). Gutenberg's concept of production control, uncertainty, and the implications for modelling production and cost, Albach, H.; Brockhoff, K.; Eymann, E.; Jungen, P.; Steven, M.; Luhmer, A. (Eds.), Theory of the Firm, Springer-Verlag, Berlin, 245-260, doi:10.1007/978-3642-59661-2_13

[3] Duque, D. F. M.; Cadavid, L. R. (2007). Lean manufacturing measurement: the relationship between lean activities and lean metrics, Estudios Gerenciales, Vol. 23, No. 105, 69-83, doi:10.1016/S0123-5923(07)70026-8

[4] Murman, E.; Allen, T.; Bozdogan, K.; Cutcher-Gershenfeld, J.; McManus, H.; Nightingale, D.; Rebentisch, E.; Shields, T.; Stahl, F.; Walton, M.; Warmkessel, J.; Weiss, S.; Widnall, S. (2002). Lean Enterprise Value: Insights from MIT's Lean Aerospace Initiative, Palgrave, New York

[5] Košturiak, J.; Frolik, Z. (2006). Lean and Innovative Enterprise, Alfa Publishing, s.r.o., Praha

[6] Papadopoulos, G.; Rikama, S.; Alajääskö, P.; Salah-Eddine, Z.; Airaksinen, A.; Luomaranta, H. (2018). Statistics on small and medium-sized enterprises, from https://ec.europa.eu/eurostat/ statistics-explained/index.php?title=Statistics_on_small_and_medium-sized_enterprises, accessed on 18-12-2019

[7] Kumar, A. S.; Suresh, N. (2008). Production and Operations Management, New Age International Pvt Ltd. Publishers, New Delhi

[8] Goldratt, E. M. (1997). Critical chain, North River Press, Great Barrington

[9] Cox III, J. F.; Schleier Jr., J. G. (Eds.). (2010). Theory of Constraints Handbook, McGraw-Hill, New York 
[10] Urban, W. (2019). TOC implementation in a medium-scale manufacturing system with diverse product rooting, Production \& Manufacturing Research, Vol. 7, No. 1, 178-194, doi: $10.1080 / 21693277.2019 .1616002$

[11] Zhou, B.; Liu, Y.; Yu, J.; Tao, D. (2018). Optimization of buffer allocation in unreliable production lines based on availability evaluation, Optimal Control Applications and Methods, Vol. 39, No. 1, 204-219, doi:10.1002/oca.2341

[12] Šaderova, J.; Kačmary, P. (2013). The simulation model as a tool for the design of number of storage locations in production buffer store, Acta Montanistica Slovaca, Vol. 18, No. 1, 33-39

[13] Yang, S. L.; Xu, Z. G.; Wang, J. Y. (2019). Modelling and production configuration optimization for an assembly shop, International Journal of Simulation Modelling, Vol. 18, No. 2, 366-377, doi: $10.2507 / \operatorname{IJSIMM18(2)CO10}$

[14] Božek, P.; Nikitin, Y.; Bezak, P.; Fedorko, G.; Fabian, M. (2015). Increasing the production system productivity using inertial navigation, Manufacturing Technology, Vol. 15, No. 3, Paper M201548, 274-278

[15] Khan, S.; Standridge, C. (2019). Aggregate simulation modeling with application to setting the CONWIP limit in a HMLV manufacturing cell, International Journal of Industrial Engineering Computations, Vol. 10, No. 2, 149-160, doi:10.5267/j.ijiec.2018.10.002

[16] Straka, M.; Malindzakova, M.; Trebuna, P.; Rosova, A.; Pekarcikova, M.; Fill, M. (2017). Application of EXTENDSIM for improvement of production logistics' efficiency, International Journal of Simulation Modelling, Vol. 16, No. 3, 422-434, doi:10.2507/IJSIMM16(3)5.384

[17] Supsomboon, S.; Vajasuvimon, A. (2016). Simulation model for job shop production process improvement in machine parts manufacturing, International Journal of Simulation Modelling, Vol. 15, No. 4, 611-622, doi:10.2507/IJSIMM15(4)3.352

[18] Cantor, D. E.; Jin, Y. (2019). Theoretical and empirical evidence of behavioral and production line factors that influence helping behavior, Journal of Operations Management, Vol. 65, No. 4, 312-332, doi:10.1002/joom.1019

[19] Munyai, T.; Makinde, O. A.; Mbohwa, C.; Ramatsetse, B. (2019). Simulation-aided value stream mapping for productivity progression in a steel shaft manufacturing environment, South African Journal of Industrial Engineering, Vol. 30, No. 1, 171-186, doi:10.7166/30-1-2089

[20] Dupal, A.; Leščišin, M.; Stern, J. (2008). Production Management (Slovak edition), Sprint vfra, Bratislava

[21] Važan, P.; Janikova, D.; Križanova, G.; Budinska, I.; Luptak, V.; Škamla, M.; Hamernik, P. (2012). Systems modeling and simulation. Simulator Witness. Exercise manual, AlumniPress, Trnava

[22] Pucha, N.; Onofrejova, D.; Takac, P. (2010). Simulation analysis of technological process of production of fireplaces in semi-automated production, Innovation Transfer (Transfer inovácii), Vol. 18, No. 3, 103-106 (in Slovak)

[23] Onofrejova, D.; Kovač, J. (2015). Processing the experimental data from simulation model of the production operation, Applied Mechanics and Materials, Vol. 816, 509-513, doi:10.4028/www.scientific.net/AMM.816.509

[24] Panda, A.; Jurko, J.; Pandova, I. (2016). Monitoring and Evaluation of Production Processes, Springer International Publishing, Basel, doi:10.1007/978-3-319-29442-1 